\title{
TELESEISMIC ANALYSIS OF THE 1980 MAMMOTH LAKES EARTHQUAKE SEQUENCE
}

\author{
By Jeffrey W. Given, Terry C. Wallace, and Hiroo Kanamori
}

\begin{abstract}
The source mechanisms of the three largest events of the 1980 Mammoth Lakes earthquake sequence have been determined using surface waves recorded on the global digital seismograph network and the long-period body waves recorded on the WWSSN network. Although the fault-plane solutions from local data (Cramer and Toppozada, 1980; Ryall and Ryall, 1981) suggest nearly pure left-lateral strike-slip on north-south planes, the teleseismic waveforms require a mechanism with oblique slip. The first event $\left(25\right.$ May $1980,16^{\mathrm{h}} 33^{\mathrm{m}}$ $44^{\mathrm{s}}$ ) has a mechanism with a strike of $\mathrm{N} 12^{\circ} \mathrm{E}$, dip of $50^{\circ} \mathrm{E}$, and a rake of $-35^{\circ}$. The second event ( 27 May $\left.19^{\mathrm{h}} 44^{\mathrm{m}} 51^{\mathrm{s}}\right)$ has a mechanism with a strike of $\mathrm{N15^{ \circ }} \mathrm{E}$, dip of $50^{\circ}$, and a slip of $-11^{\circ}$. The third event (27 May, $14^{\mathrm{h}} 50^{\mathrm{m}} 57^{\mathrm{s}}$ ) has a mechanism with a strike of $\mathrm{N} 22^{\circ} \mathrm{E}$, dip of $50^{\circ}$, and a rake of $-28^{\circ}$. The first event is the largest and has a moment of $2.9 \times 10^{25} \mathrm{dyne}-\mathrm{cm}$. The second and third events have moments of 1.3 and $1.1 \times 10^{25}$ dyne-cm, respectively. The body- and surface-wave moments for the first and third events agree closely while for the second event the body-wave moment (approximately $0.6 \times 10^{25}$ dyne- $\mathrm{cm}$ ) is almost a factor of 3 smaller than the surface-wave moment. The principal axes of extension of all three events is in the approximate direction of $\mathrm{N} 65^{\circ} \mathrm{E}$ which agrees with the structural trends apparent along the eastern front of the Sierra Nevada.
\end{abstract}

\section{INTRODUCTION}

Beginning 25 May 1980, a series of $M_{L}>6$ earthquakes occurred over a period of about $48 \mathrm{hr}$ in the Mammoth Lakes region near the California-Nevada border. The sequence was part of a general increase in seismicity throughout California (McNally, 1981) in the late 1970s. In addition, the earthquake sequence was preceded by 3 yr of local anomalous seismicity which Ryall and Ryall (1981) identified as precursory to strong earthquakes. The precursory phenomena as well as the interesting tectonic setting make this an important California earthquake series. Figure 1 locates the epicenters of the three largest events and the extent of the aftershock area. Table 1 gives the epicenter parameters (taken from Cramer and Toppozada, $1980)$.

In this study, we analyze the teleseismic records of the three largest earthquakes in the Mammoth Lakes sequence. They are all well recorded worldwide on the global digital (IDA, SRO, and ASRO) and analog (WWSSN) networks. We use the surface waves to construct an initial source model and to determine the long-period seismic moment. The teleseismic $P$ waves were used to further constrain the source orientation and to isolate source complexity.

\section{Tectonic Setting}

The Mammoth Lakes Earthquake sequence occurred on the fault system which bounds the eastern front of the Sierra Nevada where it intersects the Long Valley Caldera. The geologic setting of the area has been discussed by Bailey et al. (1976), and the major geologic features are sketched in Figure 1. The caldera was formed by a violent eruption $0.7 \mathrm{~m}$.y. ago, and evidence indicates that active volcanism has taken place in the area as recently as $450 \mathrm{yr}$ ago (Bailey et al., 1976). 
The Long Valley Caldera straddles the frontal fault system which extends north and south and exhibits spectacular normal faulting consistent with the extensional nature of the Basin and Range Province which lies to the east in Nevada. The most important fault in the epicentral region is the Hilton Creek fault which Bailey et al. (1976) estimates to have undergone several hundred meters normal displacement since formation of the caldera. Within the caldera, the offset appears much smaller, and how downfaulting along the frontal fault system is accommodated there is unkown. Bailey et al. (1976) suggest that the motion is taken up on boundary faults

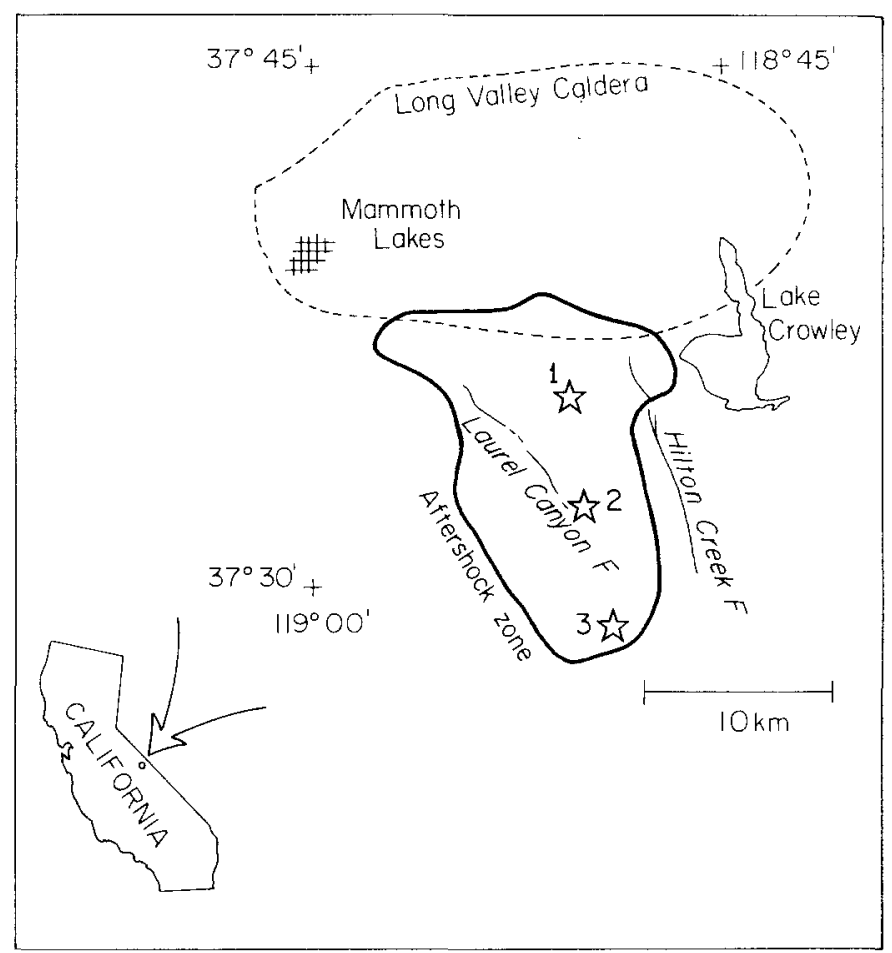

FIG. 1. Location map for the Mammoth Lakes earthquakes sequence. Event 1 is the northernmost, event 3 is the southernmost (from Cramer and Toppozada, 1980).

TABLE 1

Event Locations and ORIGIN TIME

\begin{tabular}{cccccccc}
\hline Event & Date & Origin Time & Latitiude (N) & Longitude (W) & Depth (km) & $M_{L}$ \\
\hline 1 & 25 May & $16^{\mathrm{h}} 33^{\mathrm{m}} 44.8^{\mathrm{s}}$ & $37^{\circ} 36.5^{\prime}$ & $118^{\circ} 50.8^{\prime}$ & 9.0 & 6.0 \\
2 & 25 May & $19^{\mathrm{h}} 44^{\mathrm{m}} 51.4^{\mathrm{s}}$ & $37^{\circ} 33.6^{\prime}$ & $118^{\circ}$ & $49.8^{\prime}$ & 15.0 & 6.3 \\
3 & 27 May & $14^{\mathrm{h}} 50^{\mathrm{m}} 57.2^{\mathrm{s}}$ & $37^{\circ} 30.2^{\prime}$ & $118^{\circ}$ & $49.6^{\prime}$ & 14.0 & 6.0 \\
\hline
\end{tabular}

to the west and southwest of Long Valley. Extension of the Hilton Creek fault zone into the caldera appears to have occurred as recently as $0.3 \mathrm{~m} . \mathrm{y}$. ago, possibly indicating that the caldera had cooled enough by then to support stresses large enough to generate earthquakes.

Surface breakage associated with the Mammoth Lakes earthquake sequence seems to be confined to the Hilton Creek fault and its extensions into Long Valley (Taylor and Bryant, 1980; Clark and Yount, 1981). Although earthquakes of this size often rupture the surface, it is debatable whether this surface breakage actually 
reflects coseismic fault displacement. Due to heavy snow pack, it is possible that the primary ground breakage was missed. The epicenters are located to the west of the surface trace of the Hilton Creek fault (see Figure 1). Assuming a $60^{\circ}$ eastward dip on the fault plane and a depth of $10 \mathrm{~km}$ for the hypocenters, the epicenters would have to be moved almost $10 \mathrm{~km}$ to the east if the earthquakes occurred on the Hilton Creek fault.

Fault-plane solutions based on local and teleseismic first-motion data have been published by Cramer and Toppozada (1980) and Ryall and Ryall (1981). Their solutions imply left-lateral strike-slip faulting on a north-striking fault (or rightlateral slip on an east-west fault). Such a mechanism is remarkable in that there does not appear to be any surface manifestation of north-south or east-west lateral slip on any of the mapped faults in the area. East-west trending, right-lateral slip is compatible with the Bailey $\boldsymbol{e t}$ al. model of the southwest and west wall of the Long Valley Caldera accommodating movement on the frontal fault system, in a manner analogous to oceanic transform faulting. However, the two later events are not located near the likely location of such faults.

Savage et al. (1981) have published geodetic data which indicates that, during a time period including the Mammoth Lakes earthquake sequence, measurable extension $\left(50 \mathrm{~mm}\right.$ in $25 \mathrm{~km}$ ) occurred in the direction of $\mathrm{N} 65^{\circ} \mathrm{E}$. This trend is approximately perpendicular to the alignment of epicenters and to the mapped trace of the Hilton Creek fault. They also found that purely normal slip on the Hilton Creek fault did not satisfy the measured displacements.

\section{Surface-Wave Analysis}

Data. Three-component, long-period seismograms recorded digitally on the SRO, ASRO, and IDA networks comprised the data used for the surface-wave study. Although the largest event is fairly small $\left(m_{b}=6.2\right)$, the high-quality digital data enabled us to use the first and second passage of the fundamental-mode Rayleigh and Love waves. Using these data, the source inversion formulation as described in Kanamori and Given (1981) is applied.

Figure 2 shows the distribution around the epicenter of the stations which recorded the seismograms used in the inversion. An antialias filter described by Kanamori and Stewart (1976) was applied to remove periods less than $30 \mathrm{sec}$ from the SRO and ASRO seismograms. The records were then decimated to a sample interval of $10 \mathrm{sec}$. This processing aided the visual evaluation of the data quality and the windowing of the data to isolate the long-period wave groups. The filter response was removed during the inversion of the data.

As discussed in the previous studies using a moment tensor inversion technique [e.g., Patton and Aki (1979)], the inversion works best at long periods where the phase velocity and $Q$ are more accurately known and where the propagation distance (in wavelengths) from the source to receiver is small. For the largest Mammoth Lakes event, the (longest) period which yielded good results was about $200 \mathrm{sec}$. At this period, the Rayleigh-wave amplitude and phase data could be used for determination of the source strength and initial phase. The Love-wave amplitude data were also considered reliable; the Love-wave phase data were not used since the phase velocities are not determined accurately enough. At periods shorter than about $200 \mathrm{sec}$, we used only amplitude data for both wave types. Omission of the phase data increases the ambiguity in the solution (the slip is only determined modulo $180^{\circ}$ ) but important constraints can still be obtained.

Inversion: the first event. We corrected the spectra of the long-period fundamental-mode surface waves for propagation and attenuation to obtain an estimate of the 
source amplitude and initial phase. Then, assuming an elastic structure for the source region, we can extract the source parameters by fitting the azimuthal variation of the amplitude and phase. The excitation functions appropriate for a continental source at a depth of $10 \mathrm{~km}$ were taken from Ben-Menahem et al. (1970). Two source formulations are used in the technique. We can assume that the source was a deviatoric stress drop and use the moment tensor formulation of Gilbert (1970), or we can describe the source excitation as a shear dislocation (fault) (e.g., Ben-Menahem et al., 1970).

As discussed by Kanamori and Given (1981), the full moment tensor is indeterminate for a source at the free surface because three components of the stress drop $\left(\sigma_{z x}, \sigma_{z y}, \sigma_{z z}\right)$ are zero. For example, to create a vertical dip-slip point dislocation (the $M_{x z}$ and $M_{y z}$ contribution to the excitation) no applied stress is required, consequently, no seismic waves are excited. Evidently, this is an artifact of the

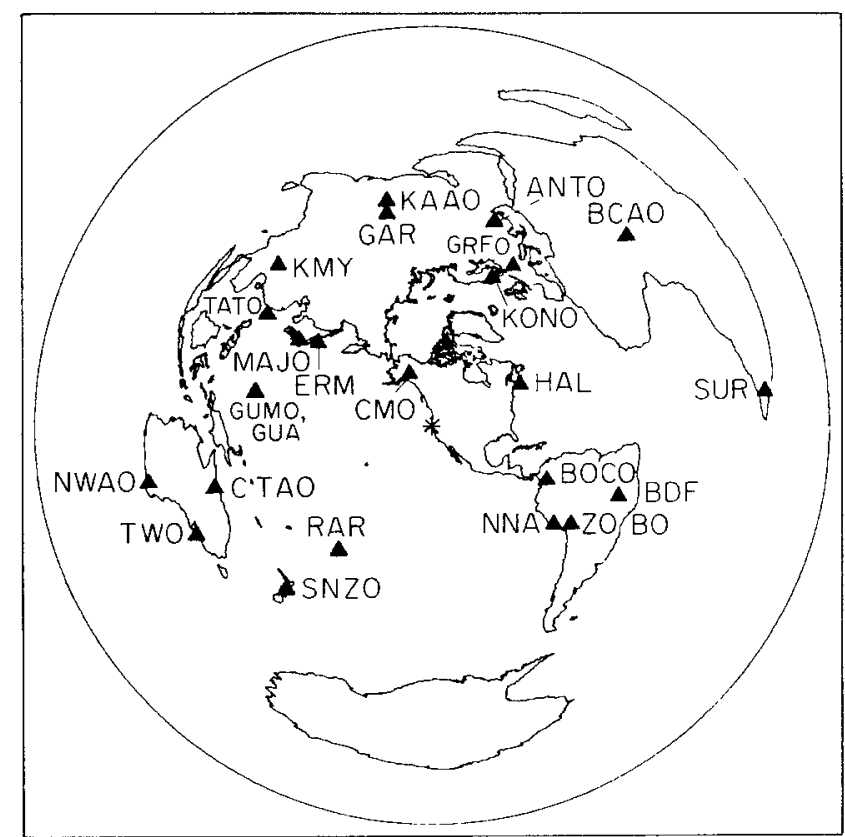

FIG. 2. Azimuthally equidistant plot centered on the epicenter of the Mammoth Lakes events. The digital seismograph stations used in the study are shown.

point-source formulation. However, to first approximation, no resolvable information is contained in the long-period waves concerning the moment elements $M_{x z}$ and $M_{y z}$. (Similarly, we cannot resolve the isotropic component of the moment tensor from the observations of long-period body and surface waves.) The problem, in terms of body waves, has been discussed by Burridge et al. (1964).

The Mammoth Lakes earthquakes were about $10 \mathrm{~km}$ deep, so at periods greater than $100 \mathrm{sec}$, the source is effectively at the free surface and only three components of the moment tensor, $M_{x x}, M_{y y}$, and $M_{x y}$, are resolvable. The use of shorter period surface waves would theoretically help, but in practice they cannot be used unless an accurate laterally heterogeneous earth model is used to correct for the propagation. At this point we are forced to use some other type of higher frequency information (where the source is a significant fraction of a wavelength from the free surface) to resolve the fault mechanism. We accomplish this by introducing con- 
straints from first-motion data (1 to $5 \mathrm{~km}$ wavelength) and from analysis of the long-period $P$-wave first motions and waveforms ( 20 to $200 \mathrm{~km}$ wavelength).

Following Kanamori and Given (1981), we first inverted for the moment tensor at period of 197 and $150 \mathrm{sec}$ with $M_{x z}$ and $M_{y z}$ constrained to be zero. The results are virtually the same at each period and are summarized as solution 1 in Table 2 and Figures 3 and 4 . The moment tensor can be visualized as three orthogonal force couples, given by the eigenvalues and the eigenvectors of the moment tensor: a vertically oriented compressional couple of magnitude $1.33 \times 10^{25}$ dyne-cm, a compressional couple oriented $\mathrm{N} 22^{\circ} \mathrm{W}$ with magnitude $1.35 \times 10^{25}$ dyne-cm, and an

TABLE 2

\begin{tabular}{|c|c|c|}
\hline \multicolumn{3}{|c|}{ Event $1^{*}$} \\
\hline Event 1 & $T=197 \mathrm{sec}$ & $T=150 \mathrm{sec}$ \\
\hline \multicolumn{3}{|c|}{ Solution $1 M_{x z}=M_{y Z}=0$, constrained } \\
\hline$M_{x y}$ & $-1.28 \pm 0.15$ & $-1.42 \pm 0.11$ \\
\hline$M_{y y}-M_{x x}$ & $3.11 \pm 0.24$ & $2.99 \pm 0.19$ \\
\hline$M_{y y}+M_{x x}$ & $1.33 \pm 0.22$ & $1.59 \pm 0.16$ \\
\hline rms error & 1.937 & 1.732 \\
\hline \multicolumn{3}{|l|}{ Solution 2} \\
\hline$M_{x y}$ & -1.28 & -1.28 \\
\hline$M_{y y}-M_{x x}$ & 3.09 & 3.09 \\
\hline$M_{y y}+M_{x x}$ & 1.50 & 1.50 \\
\hline$\theta$ & $12^{\circ}\left(126^{\circ}\right)$ & $12^{\circ}\left(126^{\circ}\right)$ \\
\hline$\delta$ & $50^{\circ}\left(64^{\circ}\right)$ & $50^{\circ}\left(64^{\circ}\right)$ \\
\hline$\lambda$ & $-35^{\circ}\left(-134^{\circ}\right)$ & $-35^{\circ}\left(-134^{\circ}\right)$ \\
\hline$M_{0}$ & 2.85 & 2.85 \\
\hline rms error & 1.955 & 1.706 \\
\hline \multicolumn{3}{|c|}{ Solution 3 Best $45^{\circ}$ dip-slip solution } \\
\hline$\theta$ & $-20^{\circ}\left(160^{\circ}\right)$ & $-21^{\circ}\left(161^{\circ}\right)$ \\
\hline$\delta$ & $45^{\circ}\left(45^{\circ}\right)$ & $45^{\circ}\left(45^{\circ}\right)$ \\
\hline$\lambda$ & $-90^{\circ}\left(-90^{\circ}\right)$ & $-90^{\circ}\left(-90^{\circ}\right)$ \\
\hline$M_{0}$ & 2.56 & 2.56 \\
\hline rms error & 2.600 & 2.57 \\
\hline \multicolumn{3}{|c|}{ Solution 4 Best strike-slip solution } \\
\hline$\theta$ & $27^{\circ}\left(-63^{\circ}\right)$ & $28^{\circ}\left(-62^{\circ}\right)$ \\
\hline$\delta$ & $90^{\circ}\left(90^{\circ}\right)$ & $90^{\circ}\left(90^{\circ}\right)$ \\
\hline$\lambda$ & $0^{\circ}\left(0^{\circ}\right)$ & $0^{\circ}\left(180^{\circ}\right)$ \\
\hline$M_{0}$ & 2.07 & 2.15 \\
\hline rms error & 2.384 & 2.65 \\
\hline
\end{tabular}

${ }^{*} \theta, \delta, \lambda, M_{0}:$ strike, dip, slip, moment, respectively. Auxiliary planes are given in parentheses. All moments in units of $10^{25}$ dyne-cm. The rms error units are $10^{-2} \mathrm{~cm}$ sec.

extensional couple oriented $\mathrm{N} 68^{\circ} \mathrm{E}$ with magnitude $2.68 \times 10^{25}$ dyne-cm. The contraints $\left(\mathrm{M}_{x z}=M_{y z}=0\right)$ limit the solution to be a combination of pure strike-slip and $45^{\circ}$ dip-slip faults. Our solution can be decomposed into a strike-slip fault (strike: $\mathrm{N} 23^{\circ} \mathrm{E}$; dip: $90^{\circ}$; slip: $0^{\circ}$; moment: $2.68 \times 10^{25}$ dyne-cm) and a dip-slip fault (strike: N68 ${ }^{\circ} \mathrm{E}$; dip: $45^{\circ}$; slip: $-90^{\circ}$; moment: $1.33 \times 10^{25}$ dyne-cm). This result can be interpreted in two ways: (1) the source is complex and cannot be represented by a single fault model; or (2) the existence of the second fault is an artifact of the constraints $M_{x z}=M_{y z}=0$, and the source can be represented by a single fault with 
significant oblique slip (Kanamori and Given, 1982). In order to explore the possible models with a single fault, we tried to find a solution which has a similar radiation pattern and which is compatible with geological observations and first-motion data.

We first found the double-couple solutions consistent with solution 1 in Table 2 and which have the minimum scalar moment. There are two possible fault mechanisms which are shown in Figure 5a along with the long-period teleseismic firstmotion data. The scalar moment of these mechanisms is $2.6 \times 10^{25}$ dyne-cm. From the alignment of the epicenters, and the eastward dip of the dominant fault structures in the region, we prefer the mechanism with strike: $\mathrm{N} 16^{\circ} \mathrm{E}$; dip: $60^{\circ}$; slip: $-35^{\circ}$. This mechanism is in agreement with the teleseismic long-period first-motion data shown in Figure 5a.
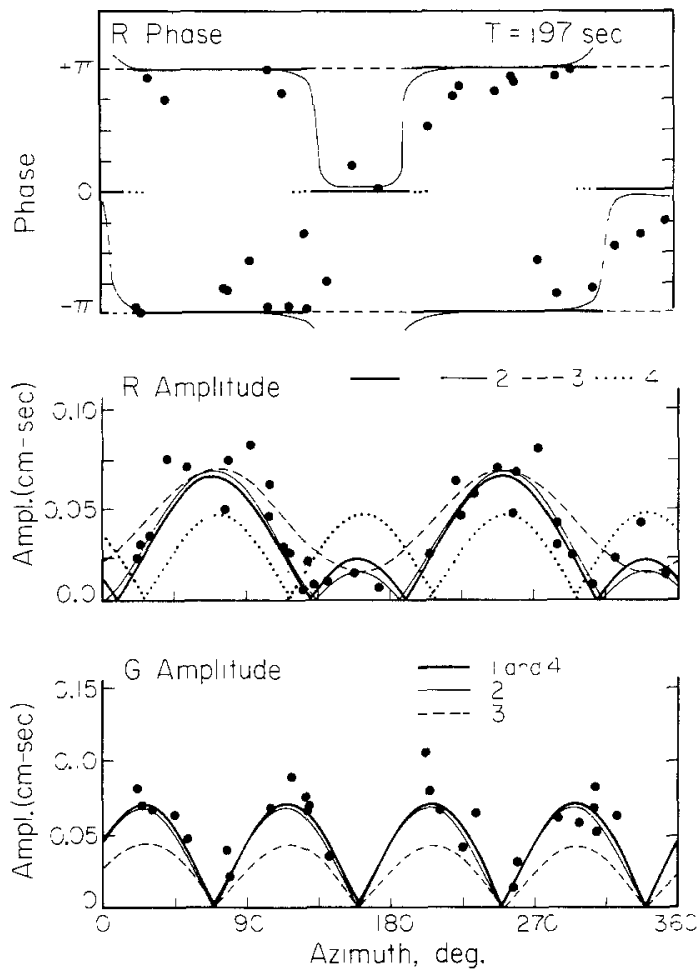

FIG. 3. Inversion results at period of $197 \mathrm{sec}$. The numbers refer to source models in Table 2. Poorly fitting phase data is associated with low-amplitude signals.

Based on body-wave modeling, we modified the initial mechanism to one with strike: $\mathrm{N} 12^{\circ} \mathrm{E}$; dip: $50^{\circ}$; slip: $-35^{\circ}$; and moment $2.85 \times 10^{25}$ dyne-cm. The fit of this solution is also shown in Table 2 and Figures 3 and 4; the mechanism is compared to the first-motion data in Figure 5. The resolvable components of the equivalent moment tensor are nearly the same as solution 1 , and, therefore, the radiation patterns are almost identical. In Figure 5b, we show the local (with a few teleseismic) first-motion data taken from Cramer and Toppozada (1980), Ryall and Ryall (1981), E. Corbett (personal communication), and R. Cockerham (unpublished data). The local data in Figure 5b appear to be incompatible with the teleseismic long-period first motions in Figure 5a. The greatest discrepancy in Figure 5b between our preferred solution and the local data is in the northeast quadrant. Long-period first 
motions in this direction are dilatational whereas the data from Ryall and Ryall (1981) are compressional. The first arrivals in this quadrant have propagated beneath the Long Valley Caldera and structural complexity could account for the discrepancy. Another interesting possibility is that the source may have initially started as a small strike-slip event (Figure 5b).

We examined other possible solutions by constraining the solution to be either a pure strike-slip fault [as suggested by Cramer and Toppozada (1980) and Ryall and Ryall (1981); see Figure 5] or a dip-slip fault (from consideration of the major geologic structures in the area). The solutions are all compared in Figures 3 and 4 and Table 2. From comparison of the rms of the error, it is clear that neither is as good a solution as the mechanisms with oblique slip. Figure 6 shows all of the solutions in Table 2 represented on the focal sphere with solution 1 represented as the equivalent double couple with minimum scalar moment. Each of the four mechanisms in Figure 6 have principal axes of extension in approximately the direction $\mathrm{N} 65^{\circ} \mathrm{E}$. This appears to be the most resolvable feature of this data.
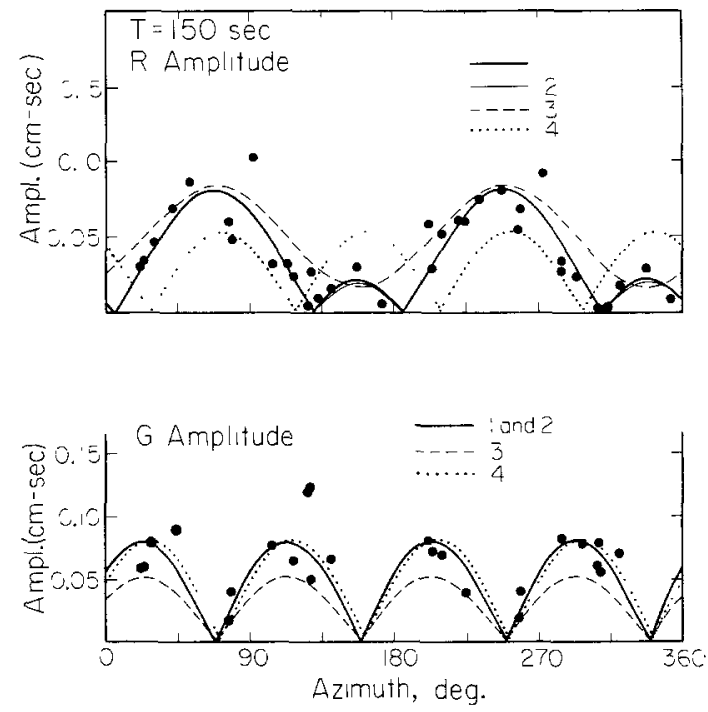

Frg. 4. Inversion results from amplitude inversion at period of $150 \mathrm{sec}$. See Table 2 for details of the models.

Inversion: the second and third events. The two other large events of the Mammoth Lakes sequence are noticeably different from the first, largest event. Figures 7 and 8 show a comparison of the filtered seismograms for the three events. In the figures, the amplitude scale is the same at a given station although it varies from station to station. The azimuthal distribution of the spectral amplitudes (at a period of $150 \mathrm{sec}$ ) of the equalized surface waves from event 1 are shown in the center of Figures 7 and 8 . These are given to show where on the radiation pattern the seismograms are from and to give an approximate idea of the scaling used to plot each seismogram. For receivers in loop directions (e.g., the Rayleigh waves at SNZO, BCAO, CTAO, and KONO and the Love waves at SNZO, MAJO, BOCO, GUMO, and KONO), the waveforms for all the events appear very similar with the first event consistently about twice as large as the second which in turn is slightly larger than the third event. However, for the Rayleigh waves, certain stations in the nodal directions for event 1 are very different. Specifically, $R_{1}$ and $R_{2}$ for CHTO is 
larger for the second event than for the first; GUMO, although quite visible for the first event, is nodal for the second; GAR and CMO show very similar levels of excitation for the first two events; and BOCO and MAJO Rayleigh waves show a change in phase between the first two events. All of these differences suggest a Rayleigh-wave radiation pattern for the second event which is more four-lobed than the first event indicating a mechanism with more of a strike-slip component.

The second and third events were too small to invert accurately using the scheme used for the first event. We therefore devised a relative inversion technique which used the differences apparent in the waveform amplitudes and which reduced errors due to inadequate knowledge of the propagation path.

The filtered seismograms shown in Figure 7 and 8 are essentially narrow-band

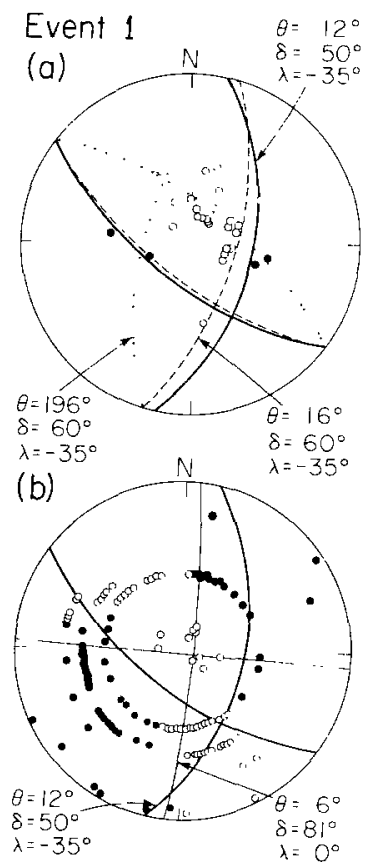

FIG. 5. (a) Long-period teleseismic first motion data for event 1. The solid lines represent the nodal planes for solution 2 in Table 2. The dashed and dotted lines represent the double couples with minimum moment and identical radiation to solution 1 at $197 \mathrm{sec}$ given in Table 2. (b) Short-period first-motion data (Cramer and Toppozada, 1980; Ryall and Ryall, 1981; unpublished data from E. Corbett and R. Cockerham). The strike-slip solution is from Ryall and Ryall (1981). All focal mechanisms are shown using lower hemisphere, stereographic projections.

records of displacement around a period of $80 \mathrm{sec}$ as a result of the instrument response and the band-pass filtering between 80 and $1500 \mathrm{sec}$. We calculated the expected spectral amplitudes at $80 \mathrm{sec}$ for solution 2 given in Table 2. The relative amplitudes of the time-domain wave groups were then used to estimate the spectral amplitudes at $80 \mathrm{sec}$ for the subequent events. For example, supposing that the predicted spectral amplitude for $R_{1}$ at KONO for the first event is $1 \mathrm{~cm}$-sec, and that the second event was measured to be an amplitude $\frac{1}{2}$ as large based on the time-domain waveform, then the spectral amplitude of $R_{1}$ at KONO for event 2 is $0.5 \mathrm{~cm}-\mathrm{sec}$. Of course this procedure is dependent on the choice of mechanism for event 1 .

The results of the relative inversion for event 2 are shown in Figure 9 and Table 3. The focal spheres for the mechanisms listed in Table 3 are shown in Figure 10 
along with available first-motion data (Cramer and Toppozada 1980). The differences between the first and second events are apparent, especially in the nodal directions for event 1 . Also the Love waves are slightly more energetic relative to the Rayleigh waves for the second event.

Solutions 1 and 2 given in Table 3 fit the data equally well. The first mechanism was constrained to be on a fault plane with the same dip angle as the source model preferred for the first event. The slip angle is much less, as we expected from visual examination of the seismograms. The strike is virtually identical to the solution for event 1 indicating that the second earthquake could have occurred on a plane of similar orientation. Mechanism 2 is obtained by inversion without constraints; again a large strike-slip component is indicated. It must be remembered that the dip angle is poorly resolved. Furthermore, because we are using only amplitude data, the sense of motion (i.e., thrust, reverse, right lateral, or left lateral) cannot be determined. It is inferred from the first-motion data and the phase of the first event.
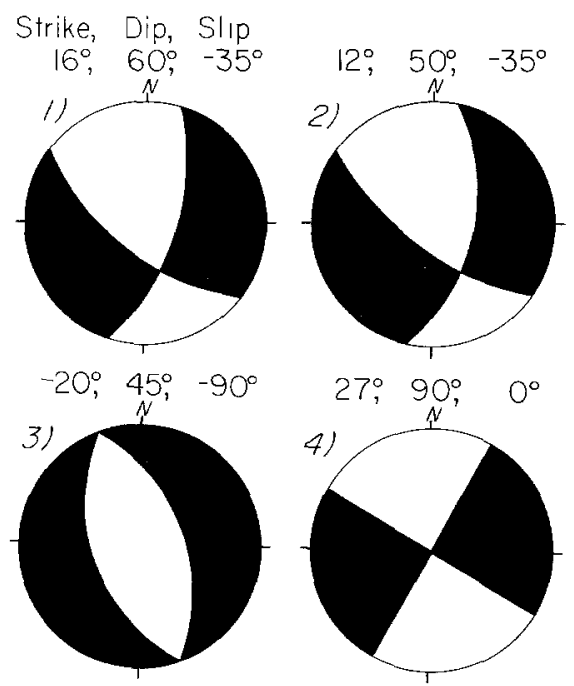

FIG. 6. Focal-sphere representation of mechanisms listed in Table 2 for $T=197$ sec. Solution I presented as double couple with minimum scalar moment and equal radiation.

The results of the inversion for the third event are given in Figure 11 and Table 4; the focal spheres and first-motion data are shown in Figure 10. Although the differences between events 1 and 3 are more subtle, a fault model with a similarly oriented plane, but with more strike-slip motion, is preferred on the basis of a smaller rms of the error. This mechanism also provides an adequate fit to the body waves as discussed in the next section.

As for event 1, the local short-period data for events 2 and 3 in Figure 10 are incompatible with the teleseismic solutions. Again, no long-period source mechanism could be obtained which fit all of the first-motion and surface-wave data.

The mechanisms derived for the second and third events depend on the solution chosen for the first. Specifically, the excitation of $M_{x z}$ and $M_{y z}$ terms become large enough at $80 \mathrm{sec}$ to contribute to the solution; these components are poorly constrained for the first event. In terms of fault-plane parameters, these components relate to the dip of the fault plane which we have fixed by first-motion data. 
Mechanisms for the second and third events are, therefore, likewise subject to any errors in these assumptions.

\section{Body-Wave ANaLysis}

The long-period $P$ waves from the Mammoth Lakes earthquake sequence were well-recorded at teleseismic distances providing an opportunity to test the validity of our surface-wave fault models. Using the surface-wave analysis to constrain the fault orientation, the $P$ waves can be used to determine the time function and seismic moment at relatively short period. Differences in the body- and surfacewave moments as well as the body-wave time function are indications of the source complexity.

Figure 12 shows a representative sample of the long-period $P$ waves. For a given

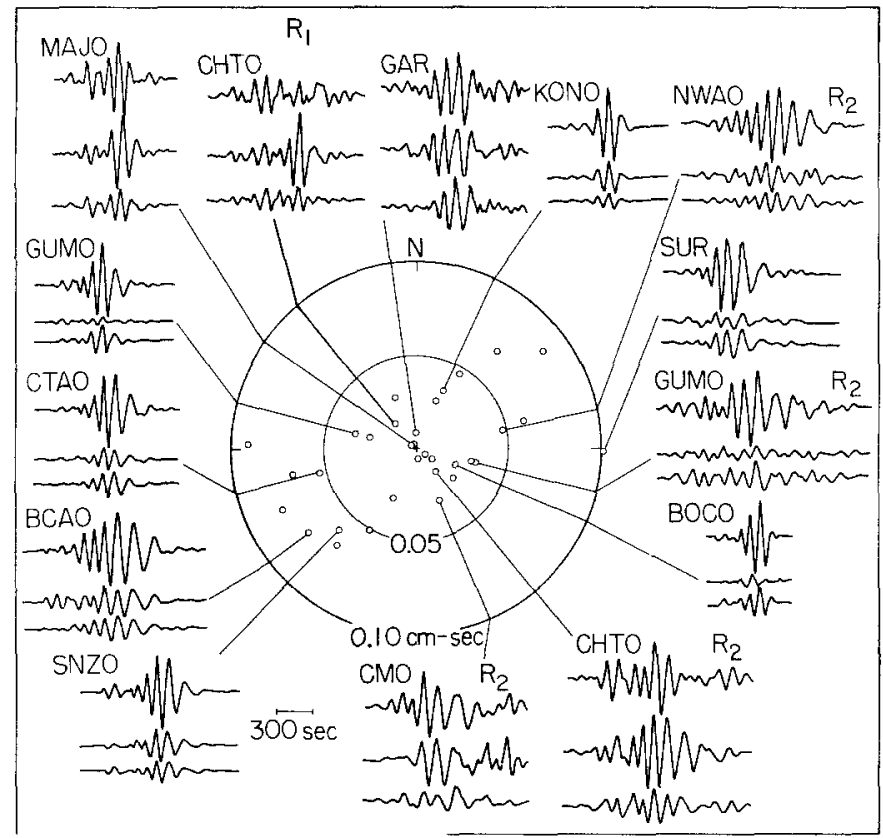

Fig. 7. Representative sample of Rayleigh waves used in the study. The seismograms have been filtered with a band-pass filter between 80 and 1500 sec. At each station, the amplitude scale is the same; the amplitude scale varies from station to station. The radiation pattern at $150 \mathrm{sec}$ for event 1 , corrected for propagation, is plotted in the center of the figure.

station, there are one, two, or three records; if a single seismogram is shown, it is for the first event, if two seismograms are shown they are for the first and third events, otherwise all three events are shown. The maximum amplitude of the upswing for a given seismogram is shown to the trace's right. Two features are apparent from this figure: (1) the first event has a consistent double-pulse nature which suggests a multiple source; and (2) the amplitude of the second event is down by a factor of at least 2 in comparison to the third event. In fact, the body waves of the second event are so small that they could seldom be observed, hence, the paucity of the waveforms in Figure 12. This is surprising since the surface-wave moments of the second and third events are nearly identical. The principal difference between the first and third events other than the source complexity is the relative importance of the second downswing. 


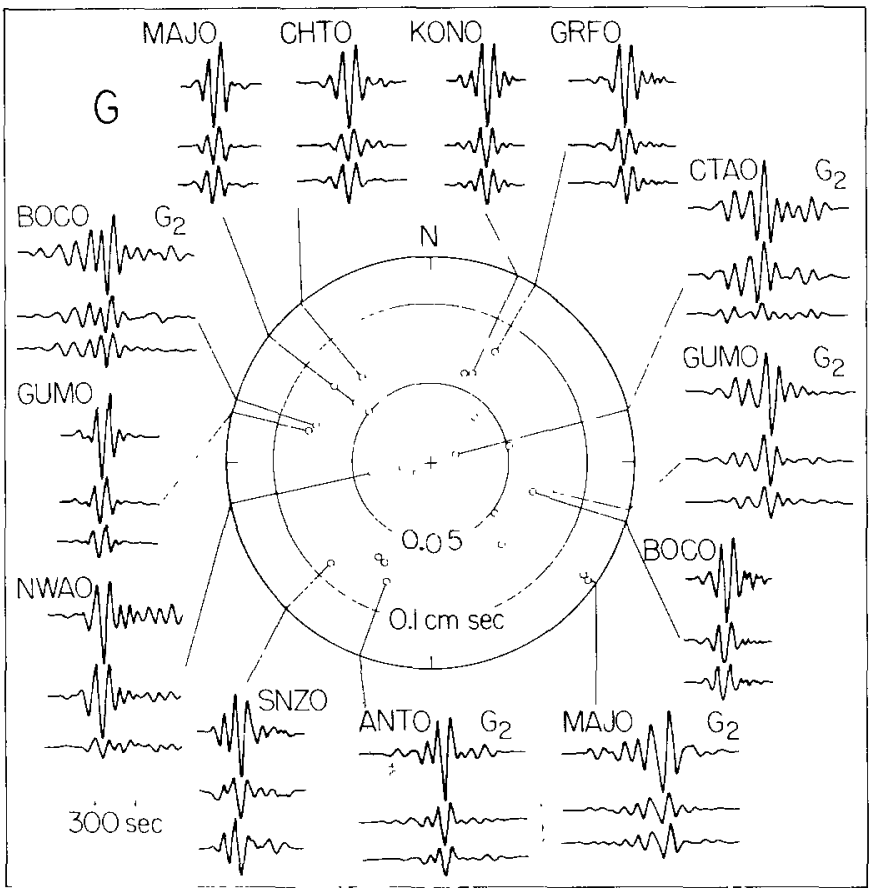

FIG. 8. Sample of the Love waves, otherwise same as Figure 7.

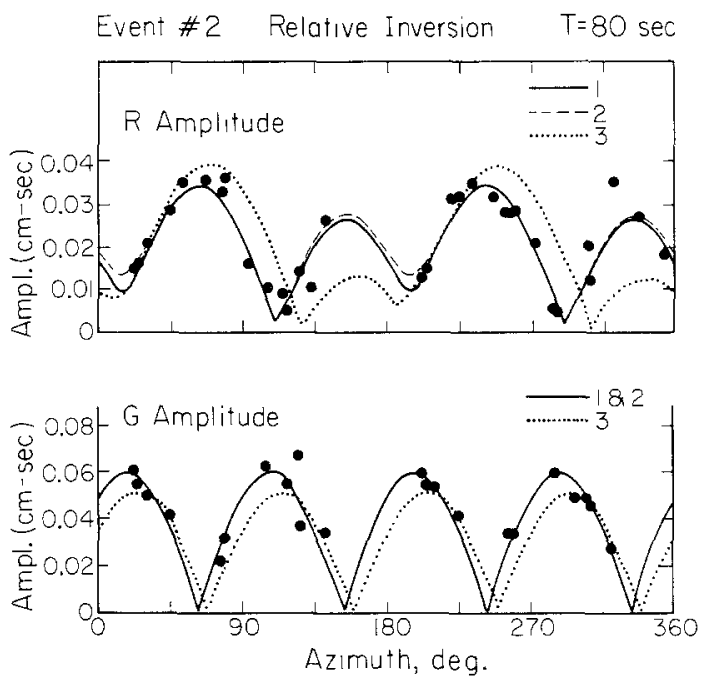

Fig. 9. Results of the inversion of relative amplitudes for the second event. Model details are given n Table 3.

TABLE 3

Event 2

\begin{tabular}{|c|c|c|c|}
\hline Solution & $\begin{array}{c}1 \\
(\delta \text { fixed) }\end{array}$ & $\begin{array}{c}2 \\
\text { (unconstrained) }\end{array}$ & $\begin{array}{c}3 \\
(\theta, \delta, \lambda \text { fixed })\end{array}$ \\
\hline$\theta$ & $15^{\circ}\left(111^{\circ}\right)$ & $16^{\circ}\left(111^{\circ}\right)$ & $12^{\circ}$ \\
\hline$\delta$ & $50^{\circ}\left(82^{\circ}\right)$ & $40^{\circ}\left(85^{\circ}\right)$ & $50^{\circ}$ \\
\hline$\lambda$ & $-10^{\circ}\left(-140^{\circ}\right)$ & $-7\left(-130^{\circ}\right)$ & $-35^{\circ}$ \\
\hline$M_{0}$ & 1.27 & 1.50 & 1.22 \\
\hline rms error & 0.505 & 0.510 & 0.983 \\
\hline
\end{tabular}



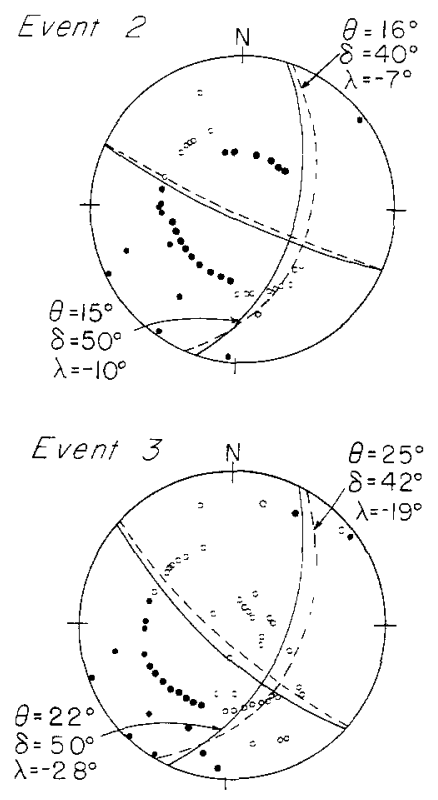

FIG. 10. First-motion data for events 2 and 3. The local data are from Cramer and Toppozada (1980) and E. Corbett and R. Cockerham (unpublished data). Nodal lines are from solutions 1 and 2 in Tables 3 and 4 .
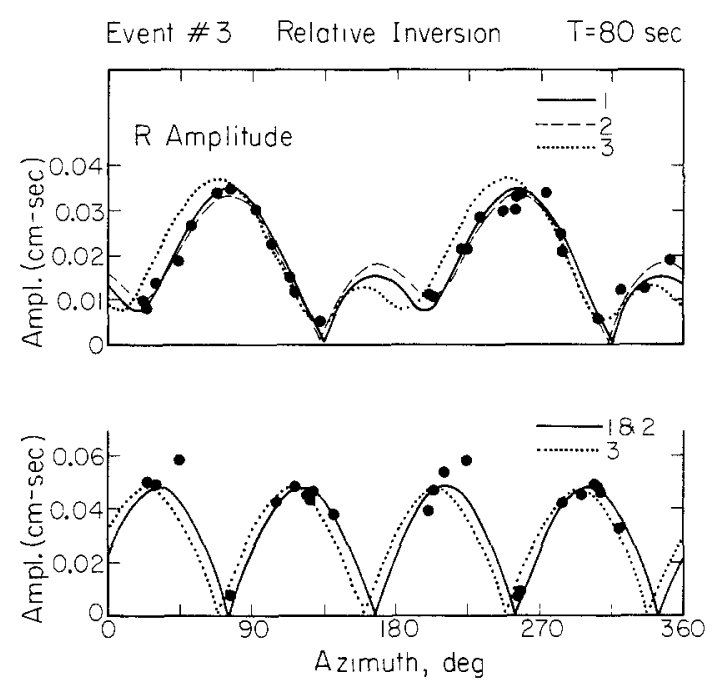

FIG. 11. Results of the inversion of relative amplitudes for the third event. Mechanism details are given in Table 4.

TABLE 4

Event 3

\begin{tabular}{lccc}
\hline \multicolumn{1}{c}{ Solution } & $\begin{array}{c}\text { 1 } \\
\text { ( } \delta \text { fixed) }\end{array}$ & $\begin{array}{c}2 \\
\text { (unconstrained) }\end{array}$ & $\begin{array}{c}3 \\
(\theta, \delta, \lambda \text { fixed) }\end{array}$ \\
\hline$\theta$ & $22^{\circ}\left(131^{\circ}\right)$ & $25^{\circ}\left(129^{\circ}\right)$ & $12^{\circ}$ \\
$\delta$ & $50^{\circ}\left(69^{\circ}\right)$ & $42^{\circ}\left(77^{\circ}\right)$ & $50^{\circ}$ \\
$\lambda$ & $-28^{\circ}\left(-136^{\circ}\right)$ & $-19^{\circ}\left(-130^{\circ}\right)$ & $-35^{\circ}$ \\
$M_{0}$ & 1.10 & 1.21 & 1.13 \\
rms error & 0.432 & 0.402 & 0.660 \\
\hline
\end{tabular}


The body-wave analysis consisted of matching the observed teleseismic waveforms with synthetic seismograms computed with generalized rays for a point-shear dislocation (see Helmberger, 1974; Langston and Helmberger, 1975). For teleseismic $P$-waves, three basic rays are used: $P ; p P$; and $s P$. The synthetic seismogram is the sum of the displacements at a receiver on the free surface associated with these rays convolved with an instrument, an attenuation operator, and a source time function. Only $P$ waves recorded at distances beyond $30^{\circ}$ were modeled. A Futterman attenuation operator with $t / Q$ of $0.75 \mathrm{sec}$ was used to approximate the effects of anelasticity. A half-space velocity model $(\alpha=6 \mathrm{~km} / \mathrm{sec}, \beta=3.4 \mathrm{~km} / \mathrm{sec}, \rho=2.7 \mathrm{gm} /$ $\mathrm{cm}^{3}$ ) was used, and the appropriate source depths were taken from Cramer and Toppozada (1980). The modeling procedure was a trial-and-error fit of the synthetics to the observations. The best fit was sought in terms of a time function parameterized by a trapezoid as described in Helmberger and Malone (1975).

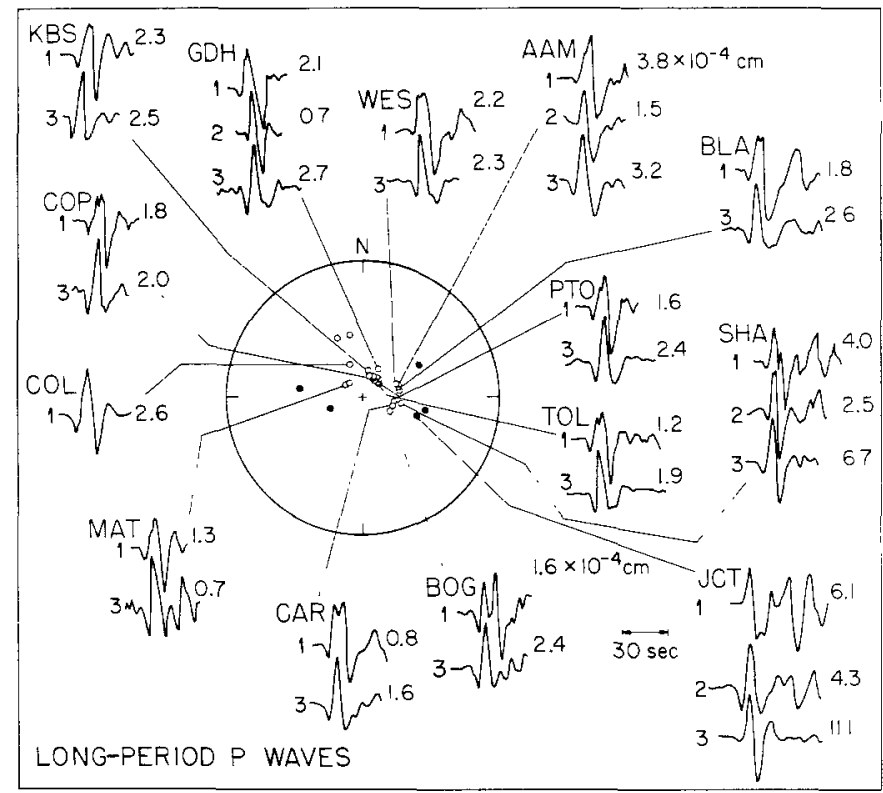

Fig. 12. A comparison of the long-period $P$ waves for the Mammoth Lakes sequence. The event number is denoted to the left of each trace and the maximum upswing amplitude is given to the right.

Figure 13 shows a comparison of the synthetics for the best-fitting point-source model and the data for the first event. The model has two sources separated in time by $4 \mathrm{sec}$. The first source has a depth of $9 \mathrm{~km}$ while the second source is $7 \mathrm{~km}$ deep. Both sources have a symmetric trapezoidal time function with a rise/fall time of 1 sec and a top of 2 sec; the first source is 80 per cent of the size of the second. Both sources are constrained to have a fault orientation of strike $=12^{\circ}$, dip $=50^{\circ}$, and slip $=-35^{\circ}$. In the modeling process, it was assumed that the first source was constrained to have the surface-wave mechanism (which is consistent with the bodywave first-motion data shown in Figure 10) while the second source could be either more dip slip or strike slip. Neither case significantly improved the fit, so the starting model was used for both sources. The poorest fitting feature of the waveforms is the large downswing (15 sec after the first arrival). The relative amplitude of this downswing is consistently 2 to 3 times larger than predicted. We were unable to reproduce this feature with point sources and faulting mechanisms in a half-space. 
One possible explanation is vertical directivity. If the second source ruptured toward the surface, $s P$ and $p P$ would be larger and will give a larger downswing. Synthetics for a finite fault were generated for a fault $5 \mathrm{~km}$ long (in the vertical dimension) and the downswing increased about 10 per cent. It would be hard to justify a much larger fault dimension considering the size of the aftershock zone, so it was decided that the finite fault was not a significant improvement. Similarly, a time function with a sharp rise and a long fall time will increase the downswing, but this also causes a misfit in pulse width.

The body-wave model is based on assumptions which, admittedly, oversimplify the problem. The $P$-wave fit can probably be improved by a more detailed analysis of the long- and short-period body waves and near-source strong motion data, including in the analysis the effects of source finiteness and crustal structure. However, some general conclusions can be made. There is observable complexity in

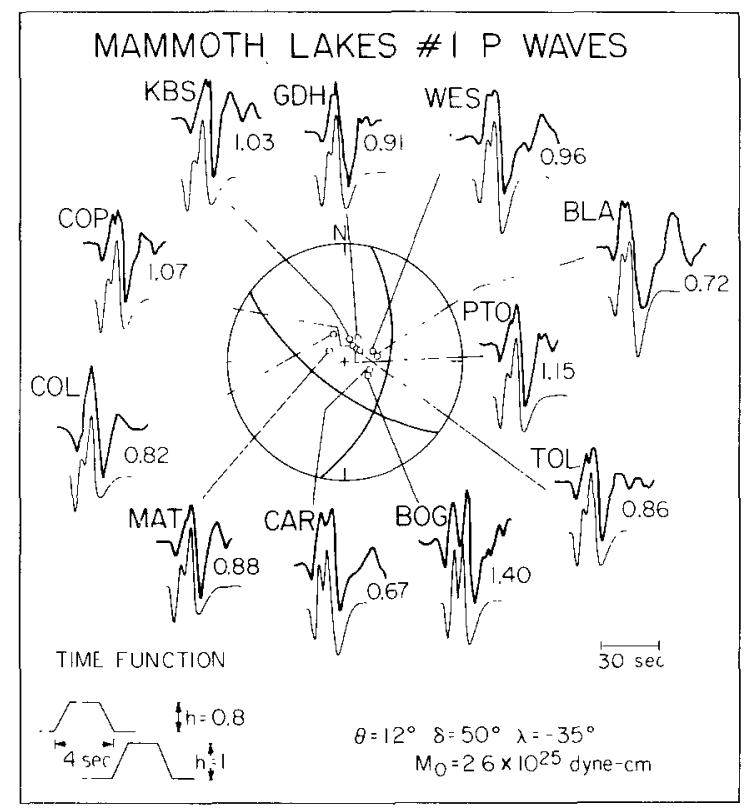

FIG. 13. A comparison of the teleseismic $P$ waves from the first event and synthetics computed for two point sources. The ratio of particular stations moment and the average moment is given to the right of each trace. The time function and mechanism used in the synthetics are shown on the bottom of the figure.

the body waves which requires at least two distinct sources. An estimate of the moment can be obtained by matching the amplitude of the upswing on each seismogram with the synthetic for that station. The body-wave moment was determined to be $2.6 \times 10^{25}$ dyne-cm.

Figure 14 shows a comparison of the synthetics for the best-fitting model and the data for the third event. The model has a single point source at $15-\mathrm{km}$ depth. The time function has a rise, top, and fall time each of 2 sec. The mechanism is that determined by the surface waves: strike $=22^{\circ}$; dip $=50^{\circ}$; and slip $=-28^{\circ}$. The synthetic fits appear quite satisfactory at all stations. The average moment was determined to be $1.2 \times 10^{25}$ dyne-cm. The ratio of station moment to average moment is shown to the right of each seismogram pair in Figure 14.

As discussed earlier, the waveforms of the second event were small, and no modeling of them was attempted. A moment can be computed by assuming the 
surface-wave mechanism (solution 1 in Table 4) and comparing the amplitudes at the stations where body waves are observed. The moment was determined to be 0.6 $\times 10^{25}$ dyne-cm.

\section{Discussion}

Our interpretation of the faulting sequence is that each of the events occurred on planes which dip approximately $50^{\circ}$ to the $\mathrm{S} 70^{\circ} \mathrm{E}$ and involved varying amounts of lateral slip. The implication is that a system of en-echelon fault structures exist at depth. Evidence for the choice of the fault plane with the northeast strike is not compelling; it was chosen simply because it implied downfaulting along an approximately north-south structure which fits well with the gross geologic features in the area. The results of the analysis do not change if the auxiliary plane is chosen for the fault plane. We note that the trend of the auxiliary plane, about $\mathrm{N} 50^{\circ} \mathrm{W}$, is

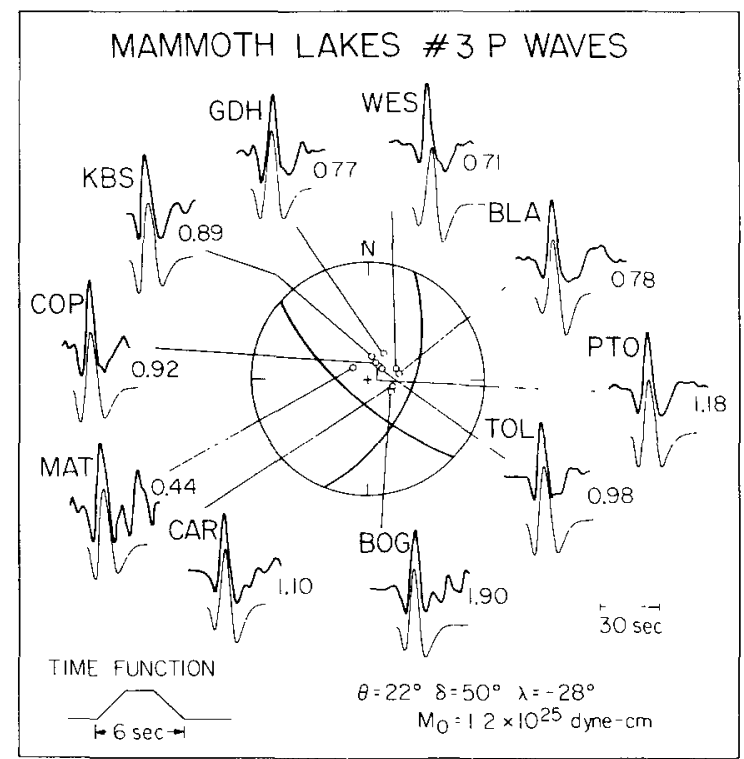

FIG. 14. A comparison of the teleseismic $P$ waves from the third event and the synthetics computed for the time function and mechanism shown. To the right of each trace is the ratio of the stations moment to the average moment.

similar to that of the Laurel Canyon fault. The principal axes of extension for all of the mechanisms in the sequence are oriented approximately $\mathrm{N} 65^{\circ} \mathrm{E} \pm 5^{\circ}$. This result is in good agreement with the direction of the extension found by Savage $e t$ al. (1981).

Fault-plane solutions for all of the events from local data (Cramer and Toppozada, 1980; Ryall and Ryall, 1981; E. Corbett, personal communication) suggest nearly pure left-lateral strike-slip displacement on north-south planes (Figure 5b). This fault orientation implies an extension axis rotated $20^{\circ}$ to the north of ours. Furthermore, in our fault models for events 1 and 3, there is a significant slip angle; approximately $0.75: 1$ dip-slip to strike-slip motion is required to fit the data for the first event. Only for the second event is a strike-slip fault compatible with our data, and in that case, a fault plane dipping $40^{\circ}$ to $60^{\circ}$ is indicated. There are at least two possible explanations for the discrepancy between the local teleseismic solutions. One might be that the local velocity models are inadequate for computing proper 
take-off angles, hence, changing the local solution slightly to agree with ours may be justified. Another possibility is that two different faulting mechanisms are involved. In this case, the beginning of the first event is strike-slip, but the long-period energy is predominantly radiated from the more dip-slip mechanism.

Because of the ground breakage on the Hilton Creek fault and the parallel trend of the epicenters, it is reasonable to propose that the earthquakes occurred on a zone of weakness associated with the frontal fault system. Direct association with the Hilton Creek fault is precluded by two observations. First, no fault plane compatible with the teleseismic data fits the trend of the epicenters and the fault. The best line of evidence constraining the strike is the relative excitation of the Love and Rayleigh waves. Taken separately, each of the radiation patterns may fit a NNW fault with normal displacement but unless a mechanism for anomalously large excitation of Love waves can be suggested, purely normal movement can be dismissed. Second, the hypocenters are located at $8 \mathrm{~km}$ west of the projected Hilton Creek fault plane at depth. Errors this large, although not impossible, are unlikely considering the station coverage in the area. Again, we note the complexity evident in the first event. The possibility that movement on the Hilton Creek fault was triggered by an initial rupture off the fault cannot be ruled out by our data set.

The proximity of the Long Valley Caldera to the epicentral region may exert an influence on the stress system. As mentioned earlier, a sharp discontinuity of the fault displacements is observed across the caldera boundary and it is not known how the normal displacements on the frontal faults is accommodated in Long Valley. One mechanism, suggested by Bailey et al. (1976), is a system of east-west rightlateral strike-slip faults along the south and southwest boundary of the caldera, where the frontal faults appear to step to the west. It is possible to interpret the Mammoth Lakes sequence within this framework, however, the absence of surface manifestation of any east-west trending structure near the epicenters, as well as the north-south alignment of the epicenters detracts from the appeal of this model.

The question of strike-slip motion aside, several interesting points can be made by comparing the three earthquakes. Both the surface- and body-wave analyses suggest that, although the tension axes remain about the same, the faulting mechanisms change during the sequence. The $M_{L}$ 's of the events (see Table 1) suggest that the three events are similar in size, yet the teleseismic analysis indicates that the first event is clearly dominant. The body-wave study indicates that the rupture of the first event took place in at least two discrete segments, and the total moment is in good agreement with the surface-wave moment. Similarly, the third event yields comparable body-wave and surface-wave moments. The second event, on the other hand, is dramatically different. The surface-wave moment is three times larger than the body-wave moment. An obvious explanation is that this event had a different stress drop, however this is not reflected in the $M_{L}$. Analysis of the nearsource and short-period data may resolve this question.

\section{Conclusions}

The source mechanisms of the largest events of the Mammoth Lakes earthquake sequence have been determined using surface waves recorded on the global digital seismograph network and long-period body waves recorded on the WWSSN network. The mechanism of the first event suggests a fault plane with a strike of $\mathrm{N} 12^{\circ} \mathrm{E}$ and a dip of $50^{\circ}$ to the southeast. Slip on the fault plane is $-35^{\circ}$ and the moment is $2.9 \times 10^{25}$ dyne-cm. Event 2 had a moment of $1.3 \times 10^{25}$ dyne-cm and a mechanism with strike; $15^{\circ}$; dip: $50^{\circ}$; and slip: $-11^{\circ}$. The third event, with a moment of $1.1 \times$ $10^{25}$, had mechanism with strike: $22^{\circ}$; dip: $50^{\circ}$; and slip: $-28^{\circ}$. The magnitudes of 
these events $\left(M_{W}\right)$ are $6.3,6.1$, and 6.1 respectively. The body-wave and surfacewave moments for events 1 and 3 agree closely, while for event 2 , the body-wave moment (approximately $0.6 \times 10^{25}$ dyne-cm) is almost a factor of 3 smaller than the surface-wave moment. The principal axes of extension for all three events is in agreement with the structural trends apparent along the eastern front of the Sierra Nevada, but the large-strike-slip component in these mechanisms is difficult to explain.

\section{ACKNOWLEDGMENTS}

We thank Rob Cockerham and Ed Corbett for letting us use some unpublished first-motion data. Steve Hartzell and Pierre Saint-Amand critically reviewed the manuscript. We gratefully acknowledge the WWSSN observatories which sent us copies of the seismograms. The IDA data was made available by courtesy of the IDA project team at the Institute of Geophysics and Planetary Physics, University of California, San Diego. This work was supported by the U.S. Geological Survey Contracts 14-08-000119755 and 14-08-0001-19270.

\section{REFERENCES}

Bailey, R. A., G. B. Dalrymple, and M. A. Lanphere (1976). Volcanism, structure and geochronology of Long Valley Caldera, Mono County, California, J. Geophys. Res. 81, 725-744.

Ben-Menahem, A., M. Rosenman, and D. G. Harkrider (1970). Fast evaluation of source parameters from isolated surface-wave signals, Bull. Seism. Soc. Am. 60, 1337-1387.

Burridge, R., E. R. Lapwood, and L. Knopoff (1964). First motions from seismic sources near a free surface, Bull. Seism. Soc. Am. 54, 1889-1913.

Clark, M. M. and J. C. Yount (1981). Surface faulting along the Hilton Creek fault associated with the Mammoth Lakes, California, earthquakes of May 1980 (abstract), Earthquake Notes 52, 45.

Cramer, C. H. and T. R. Toppozada (1980). A seismological study of the May 1980 and earlier earthquake activity near Mammoth Lakes, California, Special Report No. 150, California Division of Mines and Geology, R. W. Sherbourne, Editor, 91-130.

Helmberger, D. V. (1974). Generalized ray theory for shear dislocations, Bull. Seism. Soc. Am. 64, 45-64.

Helmberger, D. V. and S. D. Malone (1975). Modeling local earthquakes as shear dislocations in a layered halfspace, J. Geophys. Res. 80, 4881-4888.

Kanamori, H. and G. S. Stewart (1976). Mode of the strain release along the Gibbs fracture zone, MidAtlantic ridge, Phys. Earth Planet. Interiors 11, 312-332.

Kanamori, H. and J. W. Given (1981). Use of long period surface waves for fast determination of earthquake source parameters, Phys. Earth Planet. Interiors 27, 8-31.

Kanamori, H. and J. W. Given (1982). Use of long-period surface waves for fast determination of earthquake source parameters. 2. Preliminary determination of source mechanism of large earthquakes $\left(\mathrm{M}_{\mathrm{s}}>6.5\right)$ in 1980 , Phys. Earth Planet. Interiors (in press).

Langston, C. A. and D. V. Helmberger (1975). A procedure for modeling shallow dislocations, Geophys. J. 42, 117-130.

McNally, K. C. (1981). Geophysical anomalies in California: a return to normal seismicity (submitted for publication).

Patton, H. and K. Aki (1979). Bias of the estimate of seismic moment tensor by the linear inversion method, Geophys. J. 59, 479-495.

Ryall, A. and F. Ryall (1981). Spatial-temporal variations in seismicity preceding the May, 1980, Mammoth Lakes, California, earthquakes, Bull. Seism. Soc. Am. 71, 747-760.

Savage, J. C., M. Lisowski, W. H. Prescott, and N. E. King (1981). Strain accumulation near the epicenters of the 1978 Bishop and 1980 Mammoth Lakes, California, earthquakes, Bull. Seism. Soc. Am. 71, 465-476.

Taylor, G. C. and W. A. Bryant (1980). Surface rupture associated with the Mammoth Lakes earthquakes of May 25 and 27, 1970, Special Report No. 150, California Division of Mines and Geology, R. W. Sherbourne, Editor, 91-130.

SEISMOLOGICAL Laboratory

Division of Geological and Planetary Sciences

California Institute of Technology

Pasadena, California 91125

Contribution No. 3709

Manuscript received 2 November 1981 